\title{
Recollection
}

\section{China connection of the Arnold Arboretum of Harvard University}

\author{
Guihuan Luo ${ }^{1 凶}$, Ang $\mathrm{Li}^{1}$, Ming $\mathrm{Li}^{2}$ \\ ${ }^{1}$ Institute for the History of Natural Sciences, Chinese Academy of Sciences, Beijing 100190, China \\ ${ }^{2}$ Beijing Institutes of Life Science, Chinese Academy of Sciences, Beijing 100101, China \\ $\triangle$ Correspondence: guihuanl@ihns.ac.cn
}

The Arnold Arboretum of Harvard University, located in the Jamaica Plain and Roslindale sections of Boston, is famous for its collection and scientific study of ligneous species in North America and eastern Asia. In the 140-year history of the Arboretum (established in 1872), it has built a strong connection with Chinese botany and Chinese botanists, which can be traced back to over a hundred years ago.

In the late $19^{\text {th }}$ century, the first director of the Arnold Arboretum, Prof. Charles S. Sargent became interested in the flora and woody plants of eastern China and started to collect plant species from China. The collection expanded rapidly after Sargent hired British horticulturist Ernest $\mathrm{H}$. Wilson to explore and collect specimens from Hubei and Sichuan provinces in China, and the Arboretum soon became famous for its specialty in Chinese plant taxonomy, ecology and biogeography. This is also why quite a few young Chinese students chose to study botany in the Arboretum in the 1910s and 1920s, including Woon-Young Chun, Sung-shu Chien, Hsin-hsüan Chung and Hsien-Hsu Hu, who later became the founders of Chinese botany.a

After he finished his studies in the Arnold Arboretum and returned home in 1919, Woon-Young Chun (Fig. 1) immediately started to collect plant specimens in Hainan Island in south China, supported by the Shelden Fellowship from the US. His 9-month exploration in Hainan was quite fruitful with thousands of specimens collected and one book published. In 1921, Chun accepted an offer from the National Southeastern University in Nanjing and started teaching there. He also published an English book Chinese Economic Trees in 1922, the first botanical book in English by a Chinese author. He later joined the Sun Yat-Sen University in Guangzhou and founded the Institute of Agriculture and Forestry in 1929, which became one of the most important botany research institutions in China.

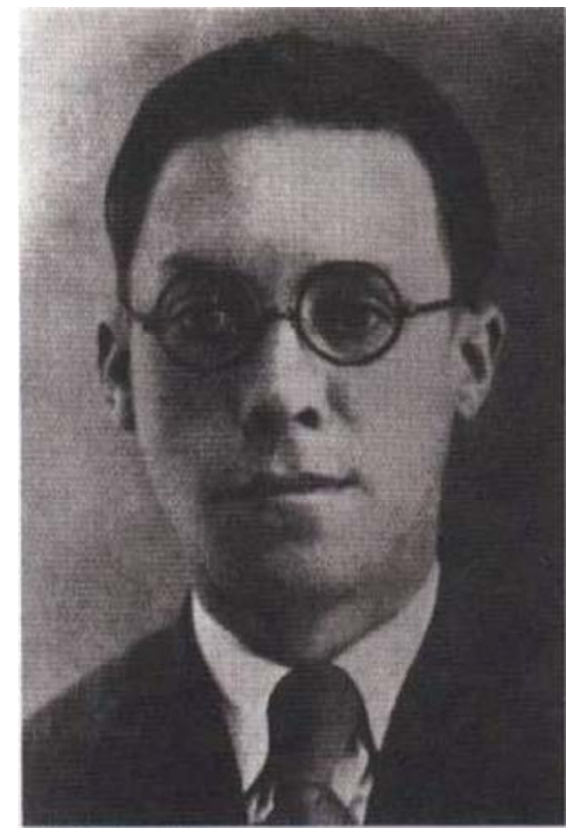

Figure 1. Woon-Young Chun (1890-1971).

Hsien-Hsu Hu (Fig. 2) is another famous Chinese botanist who received his doctor degree in the Arnold Arboretum. Even after he graduated and returned to China, he still maintained a close friendship with the Arboretum and its faculty, including John G. Jack and Elmer D. Merrill. In 1928, he co-founded the Fan Memorial Institute of Biology with Bing Chi and was appointed the director of the Botany Department, which later became a part of the Institute of Botany of Chinese Academy of Sciences. Inspired by the Arnold Arboretum, Hu had always hoped to build an arboretum in China. His dream came true in 1934 when he co-founded the Lushan Arboretum in Jiangxi Province, the first botanical 


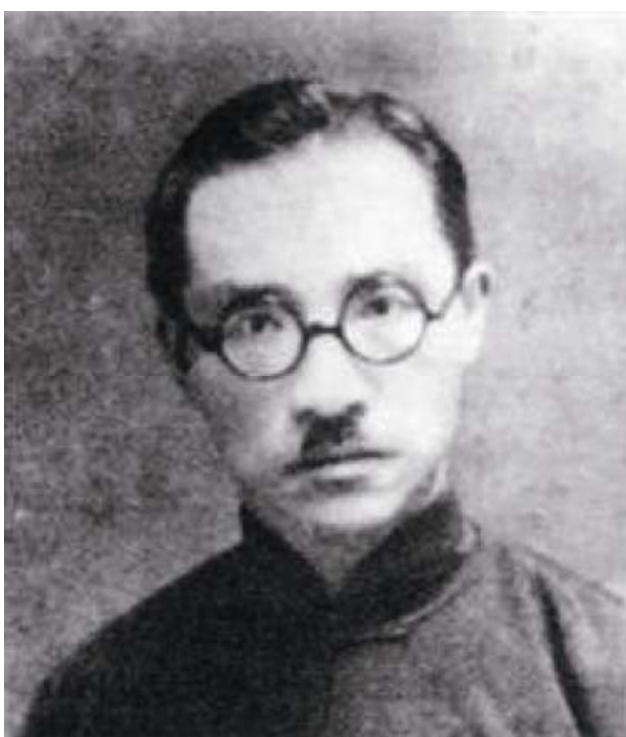

Figure 2. Hsien-Hsu Hu (1894-1968).

garden in China. Both the Fan Memorial Institute of Biology and the Lushan Arboretum have expanded their collections by exchanging specimens and seeds with the Arnold Arbo- retum.

Hsien-Hsu Hu is also well known for the identification of a living fossil, Metasequoia glyptostroboides (the dawn redwood, or Shui-Shan in Chinese), with Wan-Chun Cheng in the 1940s. Few people know that the field work where the Metasequoia specimens were collected was sponsored by Hu's friend at the Arnold Arboretum, Prof. Elmer D. Merrill. Hu also sent Merrill a package of Metasequoia seeds, which Merrill helped to distribute to the arboretums throughout the world.

The influence of the Arnold Arboretum on Chinese botanists was far more beyond collaboration and exchanges. The book written by Ernest $\mathrm{H}$. Wilson based on his exploration in Hubei and Sichuan provinces was widely spread among Chinese botanists, some of whom even followed Wilson's steps and kept on exploring the plants in those areas. Even today, botanists would re-visit Wilson's exploration sites and study the ecological changes in the areas over a hundred years.

All in all, despite the long distance and the war years, there has always been a strong connection between the Arnold Arboretum and Chinese botany/botanists, through education, collaboration and inspiration. 